\title{
Was ist Homöopathie?
}

\author{
Siegfried Adler \\ Eberswalde, Deutschland
}

Immer wieder lese ich in Ihrer Zeitschrift ForschENDE KOMPLEMENTÄRMEDIZIN mit verschiedenartigen Wertungen von und über die Homöopathie. In meiner inzwischen über 50-jährigen Erfahrungszeit in Allgemein- sowie Kinder- und Jugendmedizin habe ich mich sehr viel mit der Medizin und rationeller Wissenschaft befasst.

Ich bezweifle nicht, dass Menschen bei verschiedenen Krankheiten mittels «Homöopathie» echt geheilt werden können. Im Interesse von Wahrheit und sachlicher Gründlichkeit habe ich die Frage: Beruht das Heilungsergebnis auf den eigentlichen Fakten der Lehre Hahnemanns? Wenn immer wieder von den Vertretern der Homöopathie hervorgehoben wird, dass zur homöopathischen Behandlung nicht nur die Arzneien von Bedeutung sind, sondern auch die Anamnese einen entscheidenden Faktor darstellt, so gibt es trotzdem keine Anwendung der Homöopathie ohne homöopathische Arzneien - die seinerzeit Hahnemann auch selbst herstellte und die heute ein lukrativer Faktor der pharmazeutischen Industrie sind.

Mit dieser Tatsache sollte meines Erachtens die Frage der Wirksamkeit der Homöopathie leicht zu beantworten sein. Die individuell unterschiedliche Herangehensweise zur Diagnosefindung für die individuelle Therapie muss kein Hinderungsgrund für doppelblinde Eins-zu-eins-Testmethoden sein: Arzneiabpackungen mit und ohne die potenzierten homöopathischen Substanzen. Infolge der besonderen Herangehensweise zu Diagnose- und Arzneimittelfindung wird wahrscheinlich bei einem solchen Test eine zu beachtende Heilungsquote im Placebobereich zu verzeichnen sein - sollte der Unterschied groß sein, dann wäre die Frage der Wirkung der Homöopathie positiv beantwortet. Den Einwand wegen nicht vorhandener Homogenität der Diagnosen und der individuellen menschlichen Eigentümlichkeiten sollte man nicht akzeptieren, Kranksein oder Nicht-Kranksein ist die eigentliche Frage!

\begin{tabular}{ll}
\hline KARGER & $\odot$ 2007 S. Karger GmbH, Freiburg \\
Fax +49 7614520714 & Accessible online at: \\
$\begin{array}{l}\text { E-mail Information@Karger.de } \\
\text { www.karger.com }\end{array}$ & www.karger.com/fok
\end{tabular}

